\title{
Evaluation of Structural Stabilities for Long Span Beams at High Temperature According to Boundary Conditions Built with SM 400
}

\author{
In-Kyu Kwon \\ Department of Fire Protection Engineering, Kangwon National University, Korea
}

\begin{abstract}
Fire resistance of structural frame is very important in terms of preservation for life safety and properties. Therefore, fire tests of all structural elements are required by regulations. But, the fire resistance of long span beam made of high strength structural steels is not possible to assure the exact structural stability at fire situation, for the fire resistance of beam had been tested with a simple beam boundary condition with an ordinary strength steels and a limited beam length. In this study, to clarify the fire resistance of long span beam made of high strength structural beam, an analytic method was used using material properties at high temperature and a heat analysis, and a heat stress analysis.
\end{abstract}

Keywords-fire resistance; long span beams; SM 400; structural stability; fire design

\section{INTRODUCTION}

Recent trends for structural materials such as structural steels and concrete have been changing to high performance. The representative performance can be said a higher strength and a better function. In terms of structural steels, a better welding performance has been required for a good construction in connection. The result for it, a submarine structural steel was developed, SM 400. The SM 400 having a yield point $400 \mathrm{MPa}$ has the same mechanical properties that of SS 400. This makes the SM 400 use as a major structural steel from low-rise buildings to semi high rise buildings in Korea. However, the fire resistance for a structural member like beams built with the SM 400 is not clear, for the fire resistance of it was tested by a standard test method. The method consists of not only a specific length of beam but also a specific boundary condition. According to construction site and an architectural design concept, lots of size, length, and boundary condition can be used in real construction. Therefore, an exact fire resistance for long span beams made of SM 400 should be known to enhance fire safety of occupancy and properties. Fire resistance can be evaluated from two categories [1]. One is that a prescriptive method which can be said as a traditional method and evaluated by a single structural element by fire furnace. The other one is a fire engineering method. This is an alternative to compensate a prescriptive one and started from European area because they realized that the fire testing of structural materials are repeated continuously and consumed higher expenses. And then they developed a new method for evaluation of fire performance by calculation way using not only engineering techniques but science experiences.

\section{CHARACTERISTICS OF STRUCTURAL BEAM IN COLD AND FIRE CONDITIONS}

Beams are very important structural members in steel framed building and these transfer loads applied onto the floor. The sorts of beams can be divided into two parts. One is a statistically determinate beam and the other is a statistically indeterminate one. The determination of sorts of beam depends on the size of construction site and direction of it, and etc. But the main difference is that the statistically determinate beam cannot transfer the moment into connected adjacent beams. Therefore, the size of a statistically determinate beam is bigger than that of a statistically determinate beam, because the maximum moment of determinate beam is higher than that of indeterminate one [2]. Thus to reduce the size of beam a statistically indeterminate beam is used as a major beam in steel framed building. In aspect of structural behaviors in cold and fire stage, a deflection and a maximum load are different in two categories. In a statistically, an indeterminate beam has a lower deflection and a higher maximum load capacity than that of a statistically determinate beam in spite of cold and fire situation.

\section{CALCULATION OF STRUCTURAL STABILITIES IN FIRE SITUATIONS}

The calculation method for evaluation of fire resistance of long span beam built with a SM 400 was done with material properties at high temperature and a heat and a stress analysis. Material properties of the SM 400 are shown in Table 1 to Table 2 [3].

TABLE I. MECHANCIAL PROPERTIES OF SM 400 AT HIGH TEMPEATURES

\begin{tabular}{c|c|c|c}
\hline Sorts & Properties & Temperature & Regression equation \\
\hline \multirow{4}{*}{ SM 400 } & \multirow{3}{*}{ Yield strength } & $\mathrm{T} \subseteq 200^{\circ} \mathrm{C}$ & Cold value (235 MPa) \\
\cline { 3 - 4 } & & $200^{\circ} \mathrm{C}<\mathrm{T}$ & $-0.29 \mathrm{~T}+293.44$ \\
\cline { 2 - 4 } & \multirow{2}{*}{ Elastic modulus } & $\mathrm{T} \subseteq 200^{\circ} \mathrm{C}$ & Cold value (210GPa) \\
\cline { 3 - 4 } & & $200^{\circ} \mathrm{C}<\mathrm{T}$ & $-0.26 \mathrm{~T}+261.18$ \\
\hline
\end{tabular}

To analysis the structural stabilities such as deflection and a maximum load for each long span beam made of the SM 400, a standard fire curve defined in KS F 2257-1 was used as a fire source and 1 hour fire duration is applied [4]. The section is $\mathrm{H}-$ $400 \times 200 \times 8 \times 13$ and the boundary condition is a simple beam. 
This type is a typical set for testing of structural beams. To get the diverse fire resistance according to various length of beam, from $4100 \mathrm{~mm}$ to $5000 \mathrm{~mm}$ were designed. The $4100 \mathrm{~mm}$ in length is a standard size for testing beams. And loading points are already determined with 4 points to simulate a distributing load.

TABLE II. EXPANSION COEFFICIENTS OF SM 400

\begin{tabular}{c|c|c|c}
\hline \multirow{2}{*}{ Sorts } & Temperature & $\begin{array}{c}\text { Regression equation } \\
\left.\mathbf{( E - 0 3} /{ }^{\circ} \mathbf{C}\right)\end{array}$ & Remarks \\
\hline \multirow{3}{*}{ SM 400 } & $\mathrm{T} \subseteq 140{ }^{\circ} \mathrm{C}$ & $0.094 \mathrm{~T}-1.96$ & $\mathrm{R}^{2}=0.94$ \\
\cline { 2 - 4 } & $140<\mathrm{T} \subseteq 680{ }^{\circ} \mathrm{C}$ & $0.01 \mathrm{~T}+9.55$ & $\mathrm{R}^{2}=0.92$ \\
\cline { 2 - 4 } & $680<\mathrm{T} \subseteq 830{ }^{\circ} \mathrm{C}$ & $-0.018 \mathrm{~T}+27.56$ & $\mathrm{R}^{2}=0.98$ \\
\cline { 2 - 4 } & $830{ }^{\circ} \mathrm{C}<\mathrm{T}$ & $0.004 \mathrm{~T}+9.44$ & $\mathrm{R}^{2}=0.99$ \\
\hline
\end{tabular}

\section{MAXIMUM MOMENTS ACCORDING TO LENGTHS AT HIGH} TEMPERATURES

The maximum moments of each specimen according to boundary condition and length are shown in Table 3. Longer span beams than $4100 \mathrm{~mm}$ have a longer distance between both ends and the very adjacent applied point. In other word, the space between loading point is $820 \mathrm{~mm}$.

TABLE III. MAXIMUM MOMENTS ACCORDING TO BOUNDARY CONDITIONS AND LENGTHS OF BEAM

\begin{tabular}{|c|c|c|c|c|c|c|}
\hline \multirow{2}{*}{ Sorts } & \multirow{2}{*}{\multicolumn{2}{|c|}{ Force }} & \multicolumn{4}{|c|}{ Length(mm) } \\
\hline & & & 4100 & 4400 & 4700 & 5000 \\
\hline \multirow{3}{*}{$\begin{array}{c}\text { Simple } \\
\text { beam }\end{array}$} & \multirow{2}{*}{$\begin{array}{c}1 \\
\text { Point }\end{array}$} & $\begin{array}{c}\text { Maximum } \\
\text { moment }\end{array}$ & $2.46 \mathrm{P}$ & $2.76 \mathrm{P}$ & $3.06 \mathrm{P}$ & $3.36 \mathrm{P}$ \\
\hline & & Value (MPa) & 69.00 & 64.25 & 60.25 & 56.50 \\
\hline & $\begin{array}{c}4 \\
\text { Points }\end{array}$ & Value(MPa) & 276 & 257 & 241 & 226 \\
\hline \multirow{3}{*}{$\begin{array}{l}\text { Fixed } \\
\text { beam }\end{array}$} & \multirow{2}{*}{$\begin{array}{c}1 \\
\text { Point }\end{array}$} & $\begin{array}{c}\text { Maximum } \\
\text { moment }\end{array}$ & $1.63 \mathrm{P}$ & $1.83 \mathrm{P}$ & $1.99 \mathrm{P}$ & $2.16 \mathrm{P}$ \\
\hline & & Value(MPa) & 97.00 & 65.75 & 58.50 & 56.30 \\
\hline & $\begin{array}{c}4 \\
\text { Point }\end{array}$ & Value(MPa) & 388 & 263 & 234 & 225 \\
\hline
\end{tabular}

\section{STRUCTURAL STABILITIES FOR LONG SPAN BEAMS AT HIGH TEMPERATURES}

The history of surface temperature of beam is shown in Figure 1(a). The surface temperature of steels versus a passing time (minute) is going up rapidly. Differences of deflection among lengths are shown in Figure 1(b) to Figure 2(a). Deflections derived from a simple beam condition are higher than those from a fixed beam condition (Figure 2(b). And as the length of beam is increased, the deflection is larger in spite of beam boundary conditions. Comparisons are done according to boundary conditions and these are shown in Figure 3 (a), (b). The value from a fixed boundary condition shows a higher than that from a simple beam. A decreasing maximum load at high temperature of SM 400 showed a similar pattern with a SS 400 .

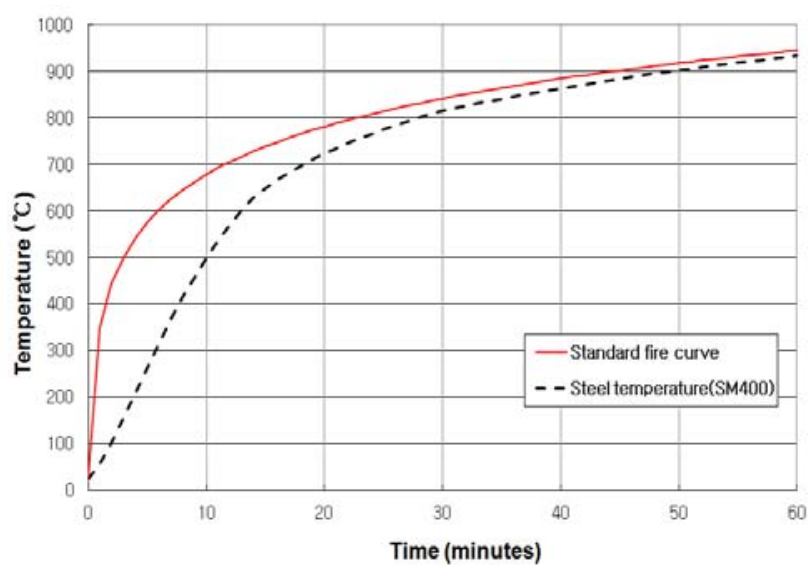

(A)FIRE CURVE AND SURFACE TEMPERATURES

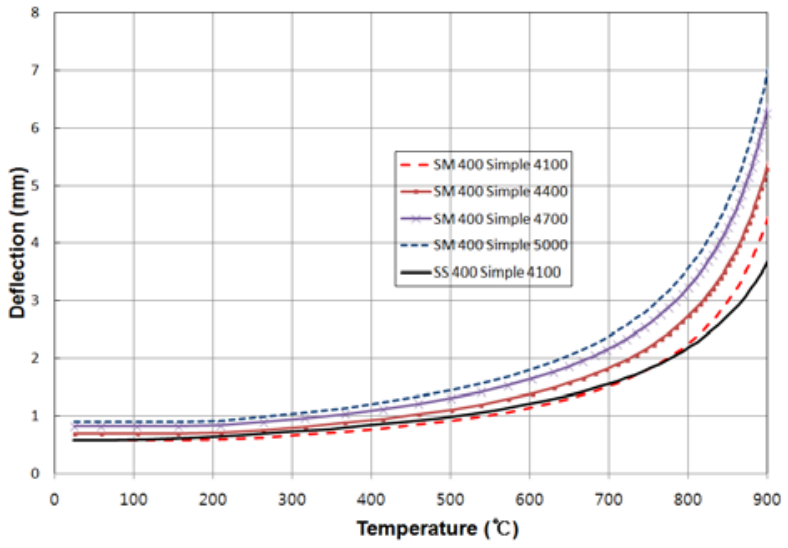

(B) DEFLECTIONS BY SIMPLE BEAM AND LENGTHS

FIGURE I. HISTORY OF SURFACE TEMPERATURES AND DEFLECTIONS VERSUS TIMES AND SURFACE TEMPERATURES

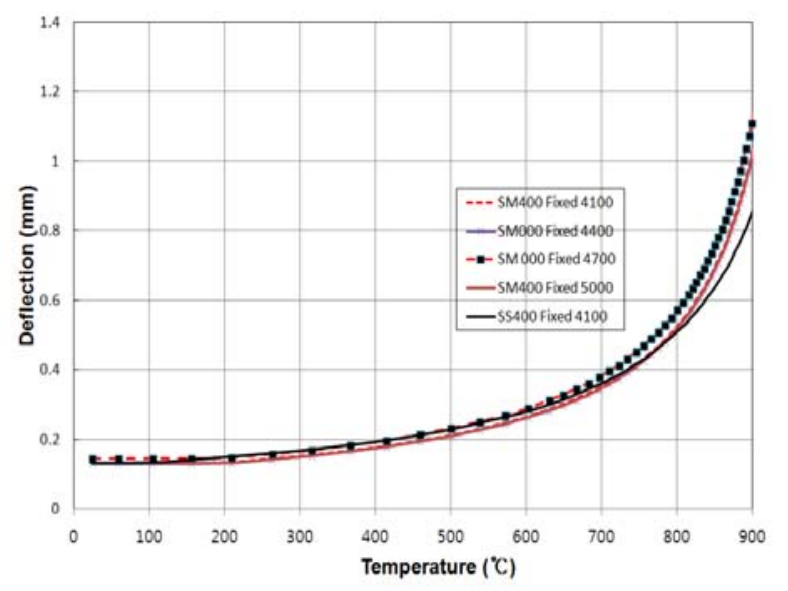

(A)FIXED BEAMS AND LENGTHS 


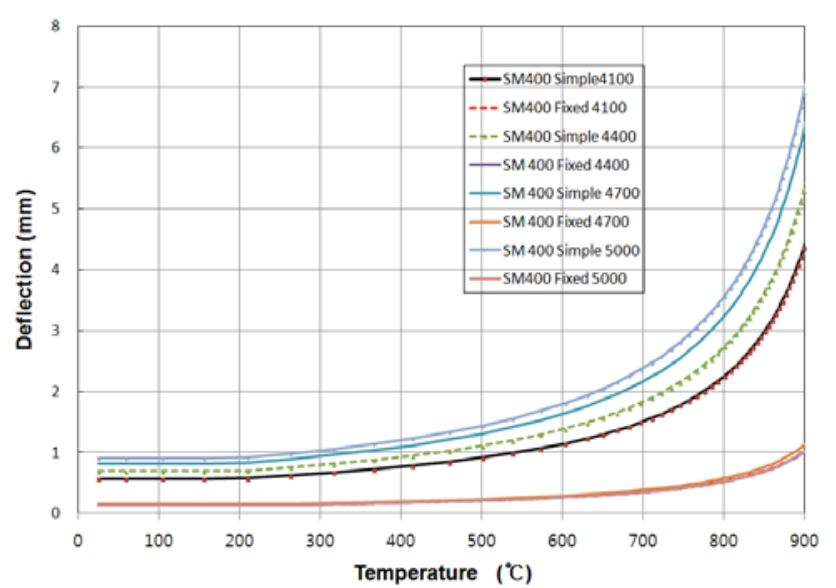

(B) COMPARISONS BETWEEN BOUNDARY CONDITIONS AND LENGTHS FIGURE II. HISTORY OF DEFLECTION VERSUS SURFACE TEMPERATURES

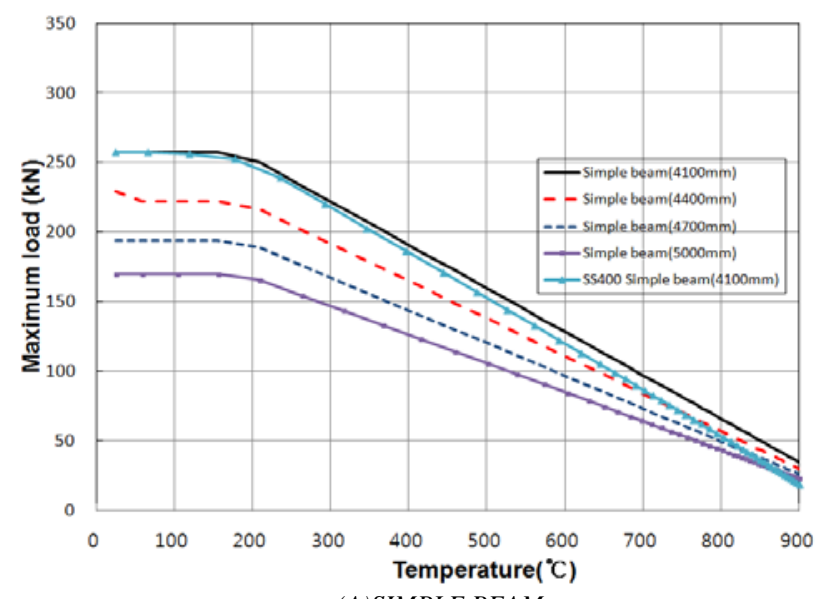

(A)SIMPLE BEAM

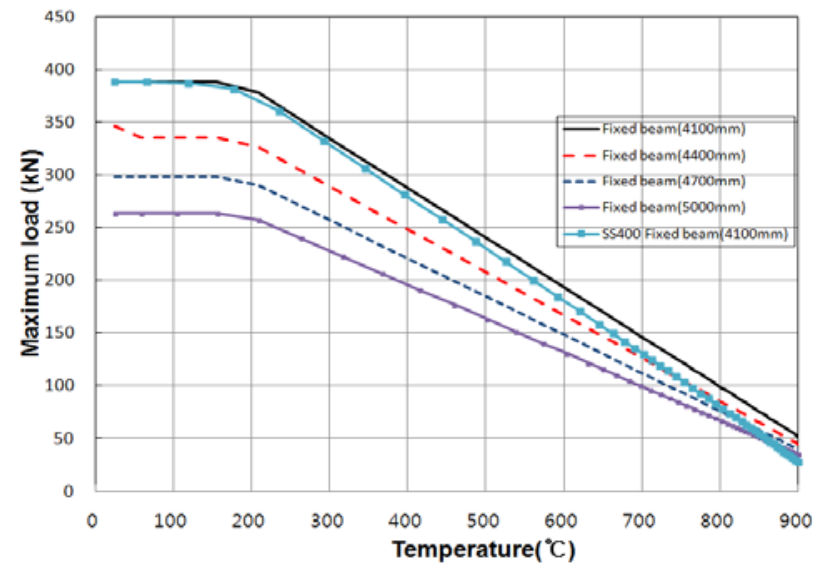

(B) FIXED BEAM

FIGURE III. COMPARISONS OF MAXIMUM LOADS VERSUS SURFACE TEMPERATURES

\section{CONCLUSIONS}

To keep fire resistance of structural element is very importance for occupancies and properties to survive from a severe fire situation. Therefore, every structural member has to sustain the load bearing capacity, insulation, and integrity during a specific fire duration. To get an exact structural stability for a long span beam built with a submarine structural steels, SM 400, a fire engineering method is used and derived the followings;

(1) As the length of beam is increased, the structural stabilities such as deflections and maximum load bearing capacity are getting worse.

(2) A fixed beam showed a better load bearing capacity than that from a simple beam conditions.

(3) Deflections according to various lengths of beam from fixed beam condition were shown very lower than those from a simple beam condition.

(4) A statistically indeterminate beam showed stronger structural stability at high temperature than that of a determinate beam.

\section{ACKNOWLEDGMENT}

This research was supported by a grant (code 15AUDPB100356-01) from an Urban-Architectural Research Program funded by Ministry of Land, Infrastructure and Transport of Korean government.

\section{REFERENCES}

[1] C. R. Barnett, G. C. Clifton, Examples of fire engineering design for steel members, using a standard fire curve versus a new parametric curve, Fire and Materials, 28, pp.309-322 (2004).

[2] D. C. Jang, S. H. Jang, "Solution of Architectural Structural Dynamic", Seoul, Korea (2005).

[3] I. K. Kwon, "Analytic Study of Structural Stability at High Temperature of Structural Beam Made of SM 400", Advanced Materials Research, Vol. 977, pp. 378-381 (2014).

[4] Korean Standard Association, KS B 0802, Method of tensile test for metallic materials, Seoul, Korea (2003). 